\title{
Transformation and Deformation Characterization of NiTiHf and NiTiAu High Temperature Shape Memory Alloys.
}

L. Casalena ${ }^{1}$, D. R. Coughlin ${ }^{1,2}$, F. Yang ${ }^{1}$, X. Chen ${ }^{1}$, H. Paranjape ${ }^{1}$, Y. Gao ${ }^{1}$, R. D. Noebe ${ }^{3}$, G. S. Bigelow $^{3}$, D. J. Gaydosh ${ }^{3}$, S. A. Padula ${ }^{3}$, Y. Wang ${ }^{1}$, P. M. Anderson ${ }^{1}$, M. J. Mills ${ }^{1}$.

1. Department of Materials Science \& Engineering, The Ohio State University, Columbus, OH, USA.

2. Los Alamos National Laboratory, Los Alamos, NM, USA.

3. NASA Glenn Research Center, Cleveland, OH, USA.

NiTiHf and NiTiAu are exciting candidates amongst an emerging class of high temperature shape memory alloys (HTSMAs), exhibiting properties conducive to actuator applications in demanding automotive and aerospace environments. NiTiHf can be tailored to achieve a highly favorable balance of properties, including high strength, stability, and work output at temperatures up to $300^{\circ} \mathrm{C}$, yet at a reduced cost compared to $\mathrm{Pt}, \mathrm{Pd}$, and $\mathrm{Au}$ containing counterparts [1]. NiTiAu shows potential for work output at much higher temperatures - where the benefits may offset cost - but additional research is needed. These investigations focus on developing a fundamental understanding of the inherent microstructure-property relationships for these NiTi-based HTSMAs. The attractive characteristics seen in many of these systems are strongly influenced by the formation of nano-scale precipitates. Advanced electron characterization techniques are used to explore the interaction of these precipitates with martensite at low temperature, and with dislocations at higher temperature. These insights are further incorporated into microstructural modeling frameworks with the aim of developing accurate simulations of polycrystalline functional response.

Two compositions of NiTiHf $\left(\mathrm{Ni}_{51} \mathrm{Ti}_{29} \mathrm{Hf}_{20}\right.$ and $\left.\mathrm{Ni}_{50.3} \mathrm{Ti}_{29.7} \mathrm{Hf}_{20}\right)$ and four compositions of $\mathrm{NiTiAu}$ $\left(\mathrm{Ni}_{11} \mathrm{Ti}_{49} \mathrm{Au}_{40}, \mathrm{Ni}_{10.3} \mathrm{Ti}_{49.7} \mathrm{Au}_{40}, \mathrm{Ni}_{10} \mathrm{Ti}_{50} \mathrm{Au}_{40}, \mathrm{Ni}_{9} \mathrm{Ti}_{51} \mathrm{Au}_{40}\right)$ were prepared at NASA Glenn Research Center. Small cylindrical bars were cut for mechanical testing and heat treatments. TEM samples were trenched and thinned to electron transparency using a focused ion beam (FIB) on a FEI Nova 600. Dislocation analysis was conducted in scanning transmission electron microscopy (STEM) mode using a FEI Tecnai F20 at $200 \mathrm{kV}$. Atomic resolution high angle annular dark field (HAADF) STEM micrographs were obtained using a probe-corrected FEI Titan 80-300 at 300kV.

Investigations have highlighted the powerful effects of temperature, composition, and aging on critical stress and transformation temperature. Figure 1 shows the results of isothermal compression tests on NiTiHf, where the increasing slope of each curve represents the critical stress to form stress-induced martensite, while the decreasing slope represents the critical stress for slip. These alloys have exhibited up to $4 \%$ fully recoverable pseudoelastic strain, and yield strengths as high as $2 \mathrm{GPa}$ [2,3]. Aging at intermediate temperature results in the formation of nano-scale H-phase precipitates, as shown in Fig. $2 \mathrm{a}, \mathrm{b}$, which have complex but beneficial effects on alloy behavior. Structural analysis of the precipitate was completed in previous publications [4], but recent efforts have been aimed at understanding how the precipitates interact with the surrounding matrix in such a way that the martensitic transformation is near-perfectly accommodated. In addition to attempts to understand precipitate-martensite interactions at low temperatures, dislocation activity at higher temperatures is also of great interest. The creation or movement of dislocations during the martensitic transformation leads to unrecovered strain, which may accumulate with subsequent cycles, leading to functional fatigue through degradation of the shape memory response. Initial dislocation analysis has shown that bands of dislocations with $<001>$-type 
Burgers vectors are most commonly observed [3]. In Fig. 2c,d, dislocations labeled 1, 2, and 3 refer to dislocations with Burgers vectors $a[001], a[010]$, and $a[100]$ respectively. Similar investigations into aged samples are currently underway. NiTiAu has been the subject of far less research interest than NiTiHf, possibly due to the high cost of $\mathrm{Au}$, however recent mechanical testing data has revealed work output capability at significantly higher temperatures than what has been observed in similar NiTi-based HTSMAs. In addition, these alloys have shown minimal variation in transformation temperature and mechanical properties as a function of composition spanning stoichiometry. This could be a result of secondary phase formation giving rise to a quasi-equiatomic state, or alternatively weak atomic site preference compared to other NiTi-based SMAs. Further investigations are in progress.

[1] H E Karaca et al, Mater Sci Tech 30 (2014), p. 1530.

[2] D R Coughlin, PhD Dissertation, The Ohio State University (2013).

[3] D R Coughlin et al, Mater Sci Eng A (2015), submitted for publication.

[4] F Yang et al, Acta Mater 61 (2013), p. 3335.

[5] The authors acknowledge funding from the US Department of Energy, Office of Basic Energy Sciences, under Grant No. DE-SC0001258.

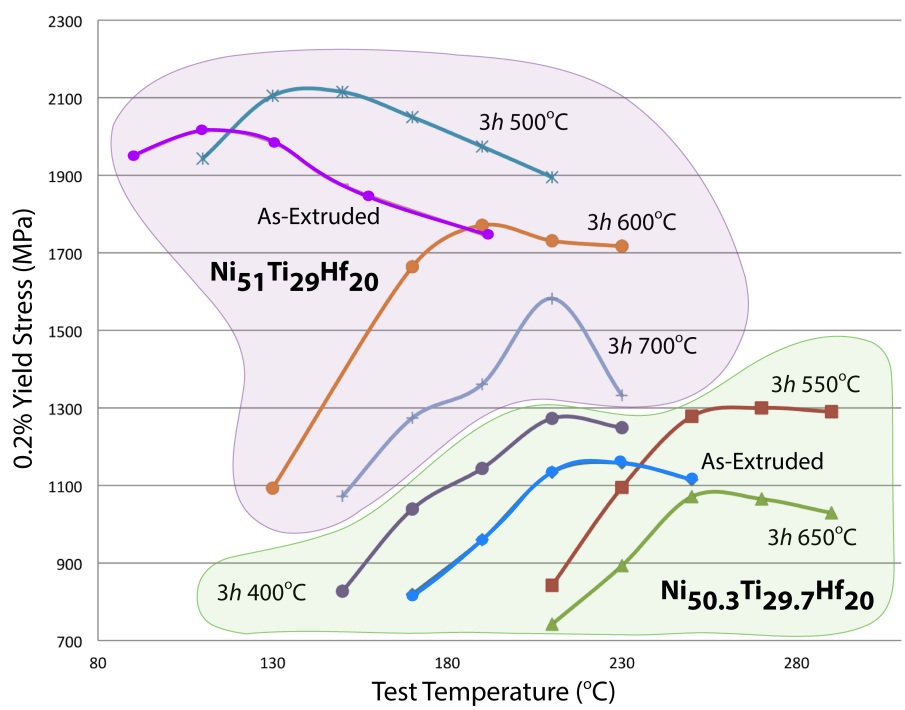

Figure 1. $0.2 \%$ offset critical stress of aged NiTiHf alloys during isothermal compression testing [2,3].
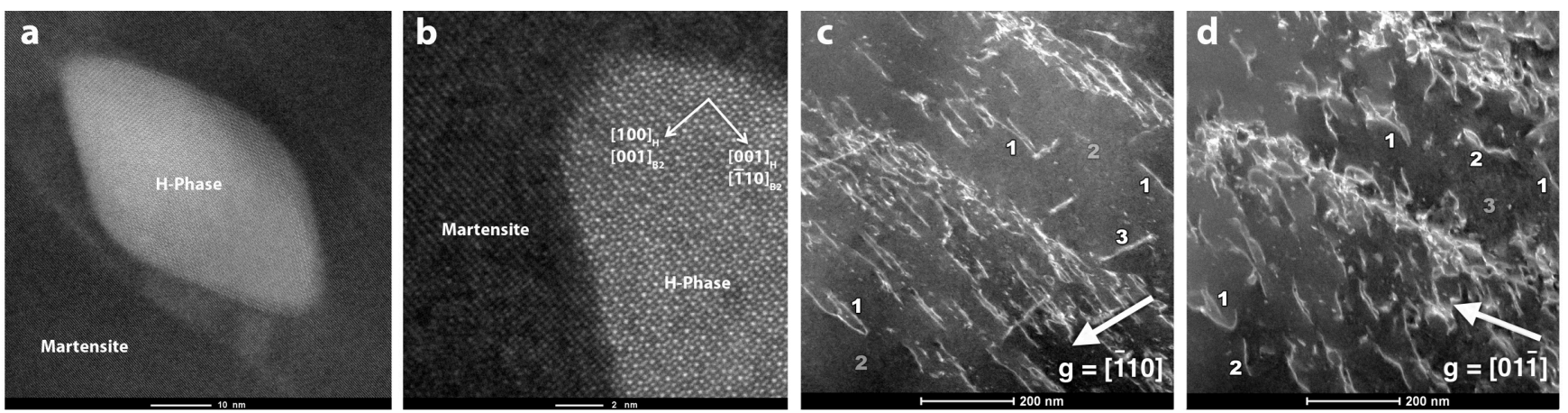

Figure 2. (a),(b) HAADF STEM images of $\mathrm{H}$-phase precipitates in $\mathrm{Ni}_{50.3} \mathrm{Ti}_{29.7} \mathrm{Hf}_{20}$ aged $3 \mathrm{hrs}$ at $650^{\circ} \mathrm{C}$, centered on the $[010]_{\mathrm{H}}\left([110]_{\mathrm{B} 2}\right)$ zone, with orientation relationship shown. (c),(d) Dark field STEM diffraction contrast images of as-extruded $\mathrm{Ni}_{51} \mathrm{Ti}_{29} \mathrm{Hf}_{20}$ post compression testing at $150^{\circ} \mathrm{C}$, showing $a<001>$ type dislocations imaged under different diffraction conditions [4]. See text for details. 